\title{
Multiple congenital stenoses of the ileum in an adult
}

\author{
M. NAUNTON MORGAN \\ From Westminster Hospital, London
}

EDITORIAL SYNOPSIS A 48-year-old woman presented with a history of abdominal pain and vomiting dating from childhood. At operation multiple ileal stenoses, believed to be of congenital origin, were found.

Cases of congenital stenosis and atresia of the small bowel have been well described and documented in children. Atresias obviously will present within the first few days of life and in most cases stenoses also will present early, most usually in the neonatal period. In Gross's series (1953), 50 out of 70 cases of intestinal stenosis presented in the first month of life, whereas only eight presented between the ages of 1 and 9 years. In that series, however, there were six cases of colonic stenosis, the age of presentation not being stated. The age of presentation is obviously governed by the degree of stenosis, and as the majority are severe, they present early. Later presentation is probably due to the change of diet from liquid to solid, superimposed inflammatory change, or the impaction of a bolus of solid food.

In a brief review of the literature, no case of congenital stenosis of the small intestine causing symptoms in adult life has been noted. In reviewing series of cases of small intestinal stenoses and atresia by various authors (Forssner, 1906; Davis and Poynter, 1922; Sheldon, 1926; Ehrenpreiss, 1943; Louw, 1952; Gross, 1953; Moore and Stokes, 1953; Weibel, 1955; Feggetter, 1955; Phelan, Lemmer, and McDonough, 1959; Benson, Lloyd, and Smith, 1960), it is seen (Table I) that multiple atresias make up about $20 \%$ of all cases of atresia of the small bowel. Others (Davis and Poynter, 1922; Spriggs, 1912) have quoted similar figures.

Multiple stenoses of the small gut, however, are extremely uncommon. Moore and Stokes (1953) describe a case of multiple diaphragmatic stenoses of the duodenum and upper jejunum. Gross (1953) and Louw (1952) in their series both include one case each but give no descriptions. Spriggs (1912), Loitman (1927), and Weibel (1955) have described also cases of multiple stenoses associated with areas of atresia. Davis and Poynter (1922) stated that this association was not uncommon but gave no figures.

The following case report is of a patient whose symptoms developed in childhood and persisted well into adult life before being diagnosed and treated.

\section{CASE REPORT}

A married woman aged 48 was admitted to hospital in October, 1962, with a history of recurrent attacks of abdominal pain and vomiting. Even as a child she apparently had abdominal pain and vomiting, being unable to take solid foods. She had frequent attacks of indigestion as a schoolgirl and at the age of $17 \mathrm{had}$ an appendicectomy for similar pain. The appendix was normal. From then until 1953, at the age of 39, she had intermittent bouts of colicky abdominal pain but from that date she began to develop a more severe, colicky, epigastric pain which was relieved immediately by copious vomiting. These attacks occurred monthly and lasted from four to seven days; they usually came on in the evening. More recently she had eaten less and although she had frequent attacks of pain, she had not vomited. She had noted that when she did not eat all day she had no pain. In the year before admission she had lost $10 \mathrm{lb}$. in weight; she was constipated and needed to take laxatives regularly but the stool was always normal and well formed.

On examination she was seen to be thin and anxious. She had a well-healed appendicectomy scar and apart

TABLE

CASES OF ATRESIA AND STENOSIS RECORDED IN THE LITERATURE

\begin{tabular}{|c|c|c|c|c|c|c|c|}
\hline \multicolumn{4}{|l|}{ Atresia } & \multicolumn{4}{|l|}{ Stenosis } \\
\hline No. of Cases & Duodenal & Jejuno/Ileal & Multiple & No. of Cases & Duodenal & Jejuno/Ileal & Multiple \\
\hline 500 & 154 & 301 & 45 & 153 & 100 & 50 & 3 \\
\hline
\end{tabular}




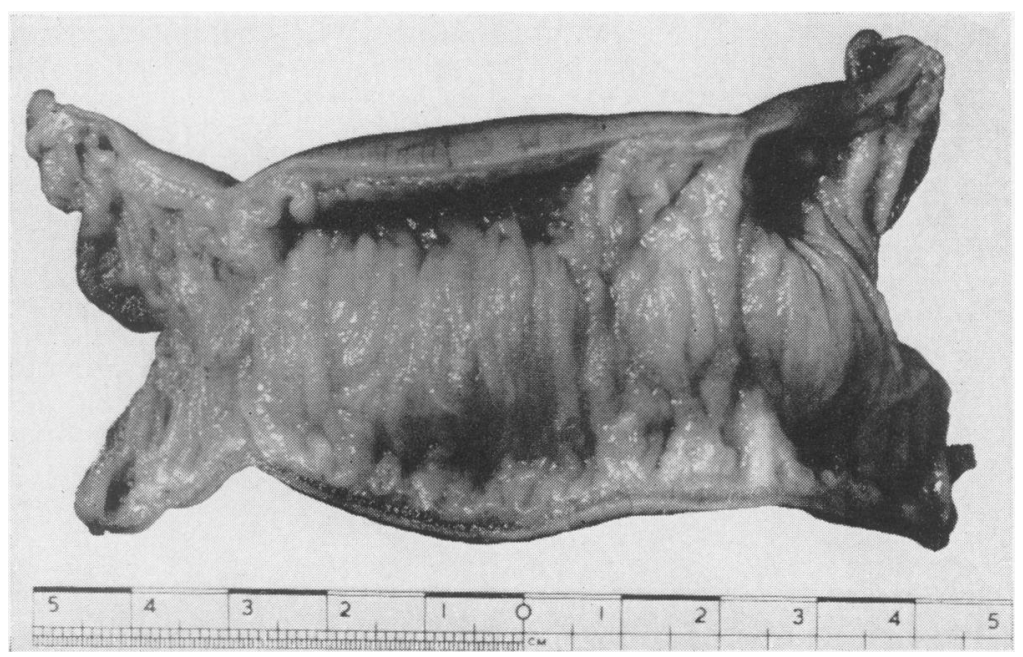

FIG. 1. Photograph of specimen showing three mucosal folds, the most distal showing a well-marked constriction.

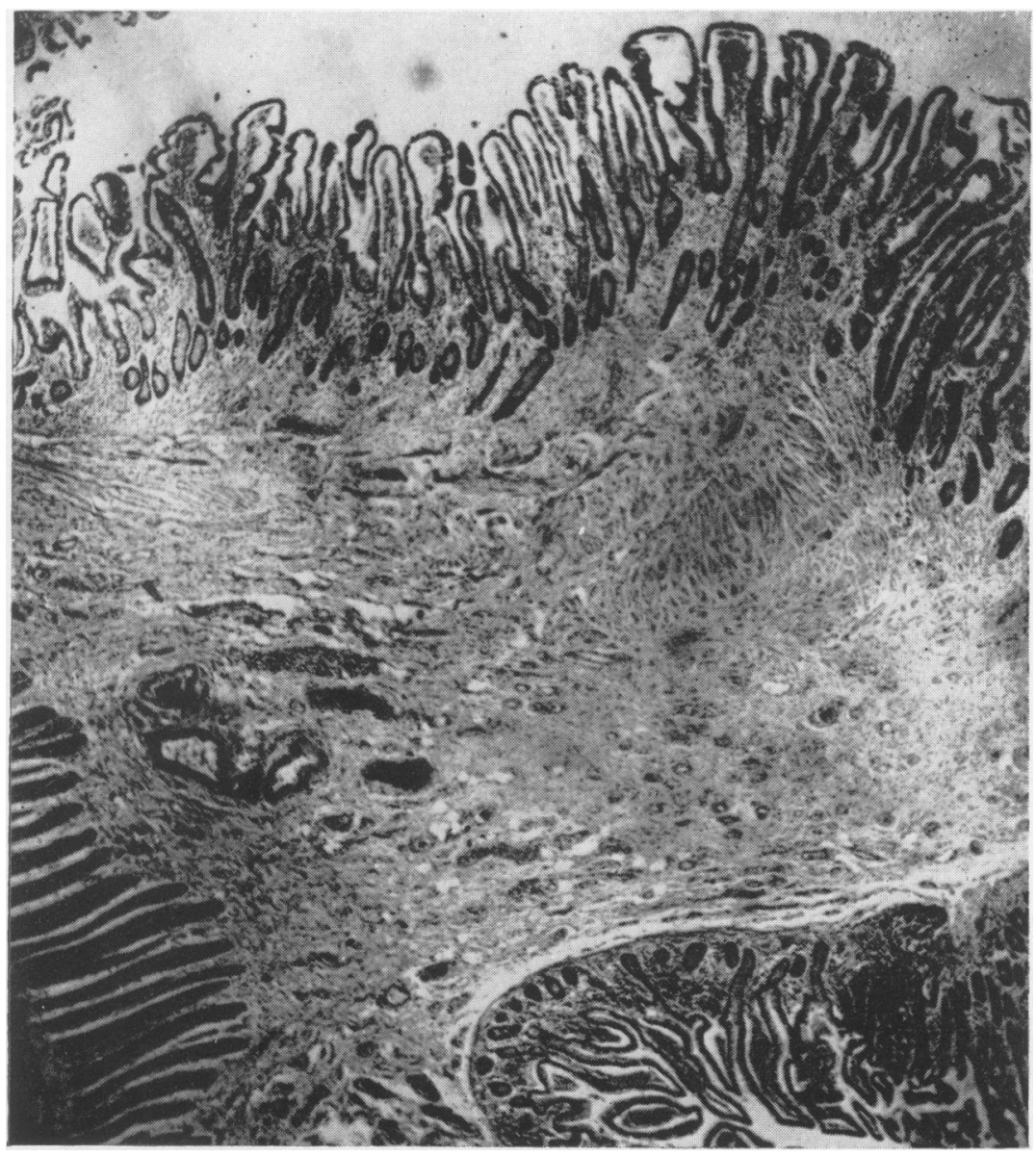

FIG. 2. Low-power view of a section through the base of the major fold. 
from slight epigastric tenderness, clinical examination was normal.

A full blood count gave: haemoglobin $82 \%$; white cell count 4,200 c/mm. (normal differential and normal films); E.S.R. $13 \mathrm{~mm}$. in one hour. The blood urea, electrolytes, liver function tests, and a chest radiograph were all within normal limits. A barium meal and followthrough examination revealed no abnormality.

Stools were normally formed and no pathogens were isolated on culture. Microscopy revealed no undigested meat fibres or obvious fat globules, nor were pus cells, ova, or parasites seen.

Laparotomy was carried out on 3 October 1962. A right para-umbilical paramedian incision was made and no abnormality was found in the abdominal contents, except in the small intestine. In the lower half of the ileum, there was an area of bowel 3 in. long which on palpation had two areas where the bowel wall appeared much thicker, corresponding to a slight narrowing seen on external examination. The bowel proximal to this area was slightly dilated. There was also a similar area in the last few inches of the terminal ileum. The mesentery of the small bowel in these areas was completely normal, with normal configuration of the blood supply, and no enlarged lymph glands. This upper segment was resected and an end-to-end anastomosis made.

The patient's post-operative progress was uneventful, and symptoms did not recur when she took solid food. When seen again 18 months after operation, the patient had had no recurrence of symptoms and was able to take a normal diet.

\section{HISTOLOGICAL REPORT}

Macroscopically the bowel showed three points of narrowing due to what appeared to be fibrous bands running the whole circumference of the wall, the most distal of these showing the well-marked constriction (Fig. 1). The intervening mucosa appeared normal. The external diameter of the proximal bowel was $4 \mathrm{~cm}$. and the distal bowel $3 \mathrm{~cm}$.
Microscopically the muscle coat and the mucosa were both normal. In the submucosa there was irregular proliferation of the connective tissue and of the muscle of the muscularis mucosa which produced three major and some minor mucosal folds. There was secondary ulceration of the mucosa at the tip of these folds. These changes closely resemble those seen in congenital stenoses in children. Section through the base of the major fold is shown below in Figure 2.

I should like to thank Mr. Robert Cox and Dr R. D. Tonkin for their advice and in allowing me to publish this case, Dr. I. M. P. Dawson for his report on the histology, and the Department of Medical Photography at Westminster Hospital.

\section{REFERENCES}

Benson, C. D., Lloyd, J. R., and Smith, J. D. (1960). Resection and primary anastomosis in the management of stenosis and atresia of the jejunum and ileum. Pediatrics, 26, 265-272.

Davis, D. L., and Poynter, C. W. M. (1922). Congenital occlusions of the intestines. Surg. Gynec. Obstet., 34, 35-41.

Ehrenpreiss, T. (1943). Quoted by Ehrenpreiss, T., and Sandblom, P. (1949). Acta paediat. (Uppsala), 38, 119.

Feggetter, S. Y. (1955). Congenital intestinal atresia. Brit. J. Surg., 42 378-388.

Forssner, H.(1906). Om de kongenitala tar-moch oesophagusatresiernas patologiska anatomi och aetiologi. Akademisk Avhandling, Stockholm, 1906.

Gross, R. E. (1953). The Surgery of Infancy and Childhood, ch. 11. Saunders, Philadelphia.

Loitman, C. (1927). Congenital occlusion of the intestines, with report of four cases. Boston med. surg. J., 197, 21-24.

Louw, J. H. (1952). Congenital intestinal atresia and severe stenosis in newborn: report on 79 consecutive cases. S. Afr. J. clin. Sci., 3, 109-129.

Moore, T. C., and Stokes, G. E. (1953). Congenital stenosis and atresia of the small intestine. Surg. Gynec. Obstet., 97, 719-730.

Phelan, J. T., Lemmer, K. E., and McDonough, K. B. (1959). Jejunoileal atresia and stenosis. Surgery, 46, 430-436.

Sheldon, W. P. H. (1926). Congenital atresia of the alimentary tract. Arch. Dis. Childh., 1, 279-284.

Spriggs, N. I. (1912). Congenital intestinal occlusion: an account of 24 unpublished cases with remarks based thereon and upon the literature of the subject. Guy's Hosp. Rep., 66, 143-218.

Weibel, L. A. (1955). Surgical management of congenital lesions of small intestines; review of 142 lesions. J. Amer. med. WomAss., 10, 411-417. 